\title{
Comparative analysis of resource utilization in integrative anthroposophic and all German pediatric inpatient departments
}

\author{
Katharina Fetz ${ }^{1 *} \mathbb{D}$, Alfred Längler ${ }^{2,3}$, Melanie Schwermer ${ }^{2}$, Clara Carvalho-Hilje ${ }^{2,3}$, Jan Vagedes ${ }^{4,5}$,
} Tycho Jan Zuzak ${ }^{2,6}$ and Thomas Ostermann ${ }^{1}$

\begin{abstract}
Background: Integrative Medicine (IM) combines conventional and complementary therapies. It aims to address biological, psychological, social, spiritual and environmental aspects of patients' health. During the past 20 years, the use and request of IM in children and adults has grown.

Anthroposophic Medicine (AM) is an IM approach frequently used in children in Germany. From both public health and health economic perspectives, it is relevant to investigate whether there are differences in the resource utilization between integrative pediatric departments (IPD) and the entirety of all pediatric departments.

Methods: Standard ward documentation data from all German integrative anthroposophic pediatric departments $(2005-2016 ; N=29,956)$ is investigated and systematically compared to data of the entirety of all pediatric departments in Germany derived from the Institute for the Hospital Reimbursement System (2005-2016, N=8,645, 173). The analyses focus on: length of stay, Diagnosis Related Groups (DRG), Major Diagnosis Categories (MDC), and effective Case Mix Index (CMI).

Results: The length of stay in the IPD ( $M=5.38 \pm 7.31)$ was significantly shorter than the DRG defined length of stay $(M=5.8 \pm 4.71 ; p<.001 ; d=-0.07)$ and did not exceed or undercut the DRG covered length of stay. Compared to the entirety of all pediatric departments $(M=4.74 \pm 6.23)$ the length of stay was significantly longer in the in the IPD $(p<.001 ; \mathrm{d}=0.12)$. The effective CMI in IPD and all pediatric departments were identical $(M=0.76)$. The frequencies of DRG and MDC differed between IPD and all pediatric departments, with higher frequencies of DRGs and MDCs associated with chronic and severe illnesses in the IPD.

Conclusions: Treatment within integrative anthroposophic pediatric departments fits well in terms of the DRG defined conditions concerning length of stay, even though integrative pediatric patients has an increased length of stay of averagely 1 day, which is most likely associated to time consuming, complex integrative treatment approaches and to a certain extend to higher amount of chronic and severe diseases.
\end{abstract}

Keywords: Integrative medicine, Pediatrics, Children, Anthroposophic medicine, Resource utilization, Cost analysis, DRG, MDC

\footnotetext{
* Correspondence: Katharina.fetz@uni-wh.de

'Department of Psychology, Chair of Research Methodology and Statistics in Psychology, Witten/Herdecke University, Alfred-Herrhausen-Straße 50, 58448 Witten, Germany

Full list of author information is available at the end of the article
}

(C) The Author(s). 2020 Open Access This article is licensed under a Creative Commons Attribution 4.0 International License, which permits use, sharing, adaptation, distribution and reproduction in any medium or format, as long as you give appropriate credit to the original author(s) and the source, provide a link to the Creative Commons licence, and indicate if changes were made. The images or other third party material in this article are included in the article's Creative Commons licence, unless indicated otherwise in a credit line to the material. If material is not included in the article's Creative Commons licence and your intended use is not permitted by statutory regulation or exceeds the permitted use, you will need to obtain permission directly from the copyright holder. To view a copy of this licence, visit http://creativecommons.org/licenses/by/4.0/ The Creative Commons Public Domain Dedication waiver (http://creativecommons.org/publicdomain/zero/1.0/) applies to the data made available in this article, unless otherwise stated in a credit line to the data. 


\section{Background}

Integrative Medicine (IM) is "healing-oriented medicine that takes account of the whole person, including all aspects of lifestyle. It emphasizes the therapeutic relationship between practitioner and patient, is informed by evidence, and makes use of all appropriate therapies" [1]. It considers biological, psychological, social, spiritual, and environmental aspects of health [2]. It is not "a discipline, a group of disorders, or a method of treatment, but an approach, a way of thinking", it "encourages clinicians and researchers to consider more than one system at a time" and "provides a framework for understanding complex and dynamic challenges" of the human organism [3]. IM is practiced worldwide and varies in its special approaches depending on cultural and national factors [4]. Therefore, IM is of particular interest from both, a public health and health economic perspective.

During the last 20 years, the implementation of integrative approaches for children has grown [2, 5-15] worldwide: IM is used in pediatrics in the USA [9, 11, 16-19], in Canada [20] and in Europe [5, 8, 21-25] in private practices, outpatient- and inpatient-departments [23]. Current literature suggests that $30-50 \%$ of parents of children with acute or chronic diseases use IM for their children [2629], while it seems to be used more frequently for children with chronic diseases in the US [16, 30-35]. IM's use for children is associated with disease severity and whether parents use IM themselves [7, 36]. IM is established in academic pediatrics and is acknowledged as an important subspecialty to address children's needs [2].

An IM approach with particular relevance in Europe and Germany is Anthroposophic Medicine (AM). It is a multimodal treatment system founded by Rudolf Steiner and Ita Wegmann in the early 1920s [37] and includes complementary pharmacotherapy, medicinal baths, rhythmical massages, compresses, and embrocation (rhythmic massages with etheric oils [38]), as well as art therapy, eurythmy, speech therapies, music therapy [39], and light/ color therapy. Consensus-based guidelines for the anthroposophic therapies for children suffering from general pediatric diseases, such as acute gastroenteritis [40] and bronchitis [41] have already been published.

In Europe, AM is integrated into conventional medical services and practiced in inpatient and outpatient settings. There are two anthroposophic hospitals in Germany that offer integrative treatment for children in distinct pediatric departments: The Gemeinschaftskrankenhaus Herdecke (community hospital) near Dortmund and the Filderklinik in Filderstadt near Stuttgart [23, 42]. A recent study of our working group found a large catchment area for these hospitals all over Germany and that parents are willing to travel further distance to get specialized integrative anthroposophic medical care for children with severe and chronic diseases [43].
However, little is known about the impact of integrative anthroposophic pediatric treatment on resource utilization as one element of economic analysis. Considering the growing costs of health care, a better understanding of resource utilization is indispensable to provide clinically effective and financially responsible treatment. Especially within the integrative field, there is a need for research evaluating the resource utilization and benefits for patients and the health care system $[41,42]$. The evaluation of resource utilization parameters thus may provide valuable information that can be considered when seeking to optimize integrative strategies in order to lower health care costs and to license and scope health care investment decisions [44].

Until today there is a need of data concerning such resource utilization parameters within integrative pediatrics $[45,46]$. Diagnoses-Related Groups (DRG), as well as length of stay are frequently used to inform health economic and resource utilization analyses in Germany, other European countries and worldwide [47-50]. Resource utilization analysis based on such data has rarely been used within integrative inpatient care [51, 52].

Therefore, the aim of the present study is to investigate parameters associated with resource utilization within integrative anthroposophic pediatric departments in Germany and to compare them systematically to representative data from all pediatric departments in Germany. Our hypotheses were that:

1 There is no difference considering the length of stay between integrative anthroposophic pediatric inpatient departments and a) the entirety of all pediatric departments in Germany, b) the DRG defined mean length of stay, as well the upper and lower limits.

2 Resource utilization indices, such as the effective Case Mix Index of integrative anthroposophic pediatric inpatient departments are comparable to the entirety of all pediatric departments in Germany.

3 There is no difference in the frequencies of DRG/ MDC between integrative anthroposophic pediatric departments and all pediatric departments in Germany.

\section{Methods}

Study design

The current study is a post hoc observational study. It was conducted according to the Declaration of Helsinki [53]. It is reported according to the STROBE guidelines for reporting observational cohort studies [54]. 


\section{Setting}

In Germany, there are two integrative hospitals focusing on Anthroposophic Medicine with pediatric inpatient departments: The Gemeinschaftskrankenhaus Herdecke $(\mathrm{GKH})$ near Dortmund and the Filderklinik in Filderstadt near Stuttgart. Both hospitals treat children with various diseases reaching from general pediatrics to specialized fields by means of an integrative approach. This approach combines conventional and complementary remedies.

The pediatric department of the Filderklinik on average treats 1245 patients per year. Beneath general pediatrics, the Filderklinik specifies in neurology, psychosomatic disorders, neonatology, endocrinology, pulmonology and cardiology for children. In the pediatric ward of the $\mathrm{GKH}, 1750$ patients are treated on average every year. The GKH practices diabetology, oncology, neonatology, rheumatology, psychosomatics and neurology in children alongside general pediatrics. The staff include physicians, nursing staff, pharmacists and therapists who are all trained in integrative medicine [43].

Diagnosis and treatment in both hospitals are in accordance with official pediatric guidelines from scientific societies and furthermore include treatment options from Anthroposophic Medicine [40, 55]. This anthroposophic treatment includes [43]: complementary pharmacotherapy, medicinal baths, rhythmical massages, compresses, and embrocation (rhythmic massages with etheric oils [38]), as well as art therapy, eurythmy, speech therapies, music therapy [39], and light/ color therapy [56]. Both hospitals are part of the German regular medical care and thus funded by the statutory health insurers.

\section{Data collection}

Patient data over the last decade (2005-2016) was derived from the standard ward documentation interface Agfa-ORBIS $^{\odot}$ in all integrative anthroposophic pediatric departments. The Microsoft Excel $^{\oplus}$-output was imported into SPSS $24^{\circ}$ (Statistical Package for the Social Sciences, IBM), cleaned and a plausibility check was performed. Furthermore, representative data was derived from the German National Consensus bureau for all pediatric departments in Germany (2005-2016).

\section{Eligibility criteria}

There were no specific criteria of eligibility in the integrative anthroposophic sample. All patient cases of all integrative anthroposophic pediatric departments in Germany treated between 2005 and 2016 were included in the integrative sample. Outliers were excluded from analysis post hoc. An outlier is an observed value which deviates so much from the other values as to arouse suspicions that it was generated by a different mechanism
[57]. In the data of the entirety of pediatric departments, outlier analysis was not possible since we were not able to gather raw data from the German consensus bureau. Consequently, exclusion of outliers was not possible.

\section{Sample}

The integrative anthroposophic sample consists of 29, 956 patient cases (Gemeinschaftskrankenhaus: $n=17$, 503 (58.4\%); Filderklinik: $n=12,453$ (41.6\%). The sample of all pediatric departments in Germany includes 48,670, 077 patient cases.

\section{Resource utilization parameters}

In Germany, it is mandatory by law for all hospitals to provide data concerning health resource utilization to the Institute for the Hospital Renumeration System (InEK) and the National Consensus Bureau. These resource utilization parameters include Diagnosis Related Groups (DRG), Major Diagnosis Categories (MDC), and effective Case Mix Index (CMI). Therefore, these parameters are considered for comparisons between the integrative anthroposophic and all pediatric departments.

\section{Diagnosis related groups and major diagnosis categories}

DRGs are assigned based on patients' ICD-diagnosis, as well as procedures, age, sex, discharge status, and the presence of complications or comorbidities. In 2003 the G-DRG system was established in Germany [58] as an adaption of the Australian DRG system. It is updated annually by the Institute for the Hospital Remuneration System (InEK).

\section{Length of stay}

The length of stay is measured in days in both samples. In the German DRG System only full days of stay are included for the length of stay [59]. Besides the length of stay, the German DRG system provides a mean length of stay, a minimum-, and a maximum length of stay for each diagnosis in the DRG-catalogue [59]. The length of stay of a patient can affect the revenue of a DRG. If the length of stay is shorter than the DRG defined lower limit, a deduction of the revenue is performed [60]. Vice versa, if the length of stay is longer than the upper limit, an additional fee is drawn [61]. For each DRG within the integrative anthroposophic sample the mean length of stay, as well as upper and lower limit for length of stay, were calculated using SPSS' Syntax function.

The data source was the DRG case-based lump sum catalogues for the years 2005-2016 derived from the homepage of the Institute for the Hospital Remuneration System [62]. 


\section{Effective case mix index}

In the German DRG-System (G-DRG), the cost weights are used to quantify a hospital's average costs per case in relation to the specific resource utilization. This includes the Case-Mix (CM), which is equal to the sum of the cost weights of all DRGs performed over a given time period. The average case weight, which is called CaseMix index (CMI), is calculated by dividing the CM by the total number of cases. Consequently, the CMI is equal to the average DRG cost weights for a particular hospital. The CMI is suitable for the comparison of the utilization of health care resources in different hospitals [63].

The effective CMI considers the deductions in the case of patient transfer or short-stay outliers, and surcharges for long-stay outliers and thus reflects the effort of a care provider for the treatment of a patient. An effective CMI value greater than 1.0 reflects a more extensive case compared to the average, while a value less than 1.0 indicates a less extensive case. In this way, the effective CMI maps the actual calculated amount for case fees [64]. Hence, in our study, the effective CMI of both samples were used for comparison of resource utilization between integrative anthroposophic and all German pediatric departments.

\section{Statistical analysis}

All statistical analyses are performed using IBM SPSS Version 24 and R Statistics. Mean differences between the integrative anthroposophic sample and all pediatric departments are tested for statistical significance by means of t-tests for independent samples. Because of cumulative testing the level of statistical significance was Bonferroni adjusted to $p<.01$. Due to the high sample- size, Cohen's d is calculated as a standardized measure of effect independent of the sample size.

\section{Results \\ Length of stay}

The mean length of stay in the integrative anthroposophic sample was 5.38 days $(\mathrm{SD}=7.31, n=29,956)$. Figure 1 illustrate the length of stay in the integrative sample compared to the DRG defined upper and lower limit of length of stay. The length of stay in the integrative anthroposophic sample did not exceed or undercut the DRG defined upper and lower limits for length of stay.

Overall, the mean length of stay in the entirety of all pediatric departments was 4.48 days $(\mathrm{SD}=7.83 ; n=38$, 724,087). A t-test for independent samples showed a significant mean difference between the integrative anthroposophic and all pediatric departments $(\mathrm{t}(38,754,041)=$ $49.41 p<.01$; Cohen's $\mathrm{d}=0.12$ ). The average length of stay per year in the integrative anthroposophic and in all pediatric departments is shown in Table 1. The length of stay in the integrative anthroposophic sample was significantly lower $(\mathrm{M}=4.74 ; \mathrm{SD}=6.23)$ than the mean length of stay defined by DRG $(M=5.8 ; \mathrm{SD}=4.71 ; \mathrm{t}(28$, 236) $=-37.74 ; p<.01$; Cohen's $\mathrm{d}=-0.07)$. The mean length of stay in the integrative anthroposophic and all pediatric departments compared to the mean length of stay proposed by DRG are shown in Fig. 2 .

\section{Effective case mix index}

The average effective CMI in the integrative anthroposophic sample is $0.76(\mathrm{SD}=1.22 ; n=29,956)$.

Overall the average effective CMI in the entirety of all pediatric departments was $0.76(\mathrm{SD}=1.97 ; n=39,159$,

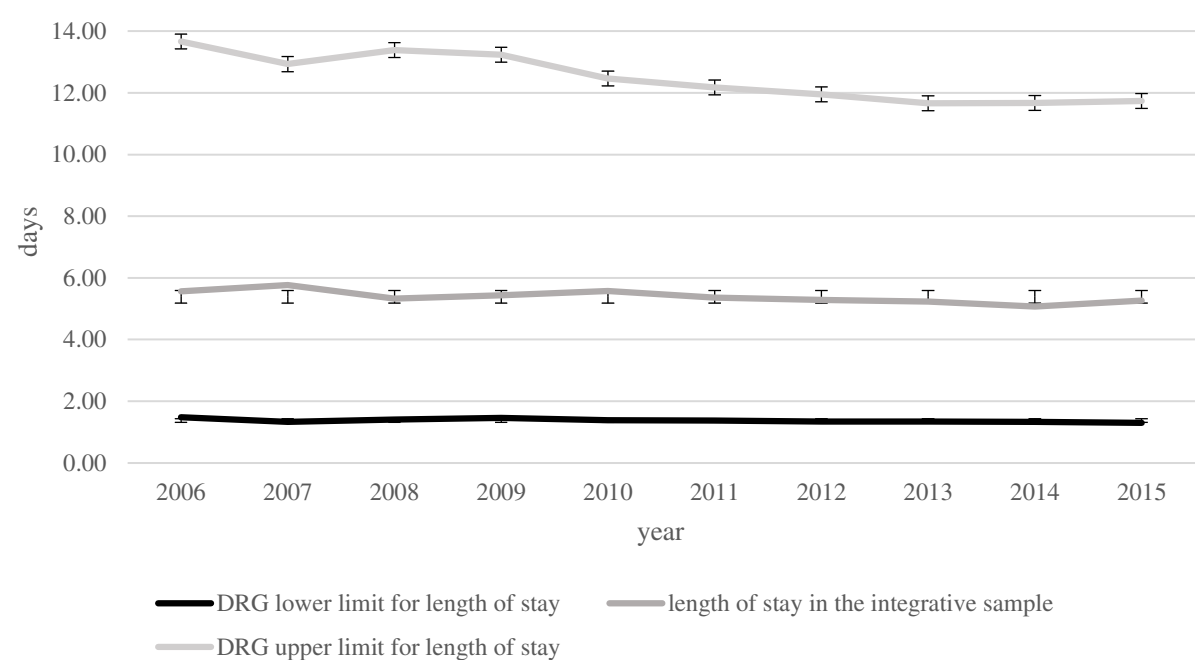

Fig. 1 Mean length of stay in the integrative anthroposophic pediatric departments in comparison to upper and lower DRG defined length of stay limits 
Table 1 Mean length of stay, CMI and Effective CMI per year in the integrative anthroposophic sample and in the conventional sample

\begin{tabular}{|c|c|c|c|c|}
\hline \multirow[b]{2}{*}{ year } & \multicolumn{2}{|l|}{ Mean length of stay } & \multicolumn{2}{|l|}{ Effective Case Mix Index } \\
\hline & $\begin{array}{l}\text { Integrative departments } \\
\text { Mean }(S D, n)\end{array}$ & $\begin{array}{l}\text { Entirety of all pediatric } \\
\text { departments Mean }(S D, n)\end{array}$ & $\begin{array}{l}\text { Integrative departments } \\
\text { Mean }(S D, n)\end{array}$ & $\begin{array}{l}\text { Entirety of all pediatric } \\
\text { departments Mean (SD, n) }\end{array}$ \\
\hline 2006 & $5.56(7.22 ; 2752)$ & 4.97 (8.10; 841,100) & $0.73(1.10 ; 2826)$ & n.a. \\
\hline 2007 & $5.76(6.96 ; 2792)$ & $4.82(7.88 ; 854,341)$ & $0.71(0.83 ; 2876)$ & n.a. \\
\hline 2008 & $5.33(6.67 ; 2819)$ & $4.65(7.63 ; 859,058)$ & $0.72(1.18 ; 2903)$ & n.a. \\
\hline 2009 & $5.44(7.20 ; 2841)$ & $4.55(7.84 ; 860,384)$ & $0.80(1.64 ; 2908)$ & n.a. \\
\hline 2010 & $5.57(7.47 ; 2790)$ & 4.55 (7.90; 860,961) & $0.78(1.33 ; 2859)$ & 0.77 (1.99; 853,146) \\
\hline 2011 & $5.36(7.23 ; 2947)$ & $4.39(7.75 ; 866,611)$ & $0.77(1.32 ; 2992)$ & $0.76(1.98 ; 858,813)$ \\
\hline 2012 & $5.28(7.53 ; 2947)$ & $4.30(7.55 ; 866,809)$ & $0.74(1.19 ; 3021)$ & $0.75(1.91 ; 858,809)$ \\
\hline 2013 & $5.23(7.69 ; 3068)$ & $4.24(8.41 ; 879,100)$ & $0.75(1.21 ; 3138)$ & $0.75(2.00 ; 871,377)$ \\
\hline 2014 & $5.07(7.01 ; 3228)$ & $4.18(7.67 ; 877,896)$ & $0.77(1.14 ; 3317)$ & $0.76(1.94 ; 870,090)$ \\
\hline 2015 & $5.27(7.92 ; 3039)$ & $4.16(7.61 ; 878,913)$ & $0.78(1.17 ; 3116)$ & $0.76(1.99 ; 870,569)$ \\
\hline overall & $5.39(7.29 ; 29,203)$ & $4.48(7.834 ; 8,645,173)$ & $0.75(1.23 ; 29,956)$ & $0.76(1.97 ; 5,182,804)$ \\
\hline
\end{tabular}

515). The average effective CMI in the integrative and all German pediatric departments per year is shown in Table 1.

\section{Diagnoses related groups}

The most frequent DRG in the integrative anthroposophic sample were B80Z (head injuries; $n=1933,6.5 \%$ ), G67B (esophagitis, gastroenteritis, gastrointestinal bleeding, ulcer, complex genesis; $n=1286,4.3 \%$ ), P67C (newborn $>2499 g$, without complex diagnosis; $n=1254$, 4.2\%), G67C (esophagitis, gastroenteritis, gastrointestinal bleeding, ulcer, uncomplex genesis; $n=1158,3.9 \%)$ and P67B ( $n=975,3.3 \%$, newborn $>2499 g$, with complex diagnosis).
In the entirety of all pediatric departments, the most frequent DRG's were G67B (esophagitis, gastroenteritis, gastrointestinal bleeding, ulcer, complex genesis; $n=561$, 552; 8.78\%) G67C (esophagitis, gastroenteritis, gastrointestinal bleeding, ulcer, uncomplex genesis; $n=440,529$; $6.89 \%$ ); B80Z (head injuries; $n=382,762 ; 5.99 \%$ ) and D63Z (otitis media or infections of the upper respiratory tract, age < 3 years; $n=310,283 ; 4.85 \%)$. The 50 most frequent DRG in both groups per year and overall are shown in the supplemental materials 1 and 2 .

\section{Major diagnosis categories}

The most frequent MDC in the integrative sample were Diseases and Disorders of the Nervous System $(n=5366$,

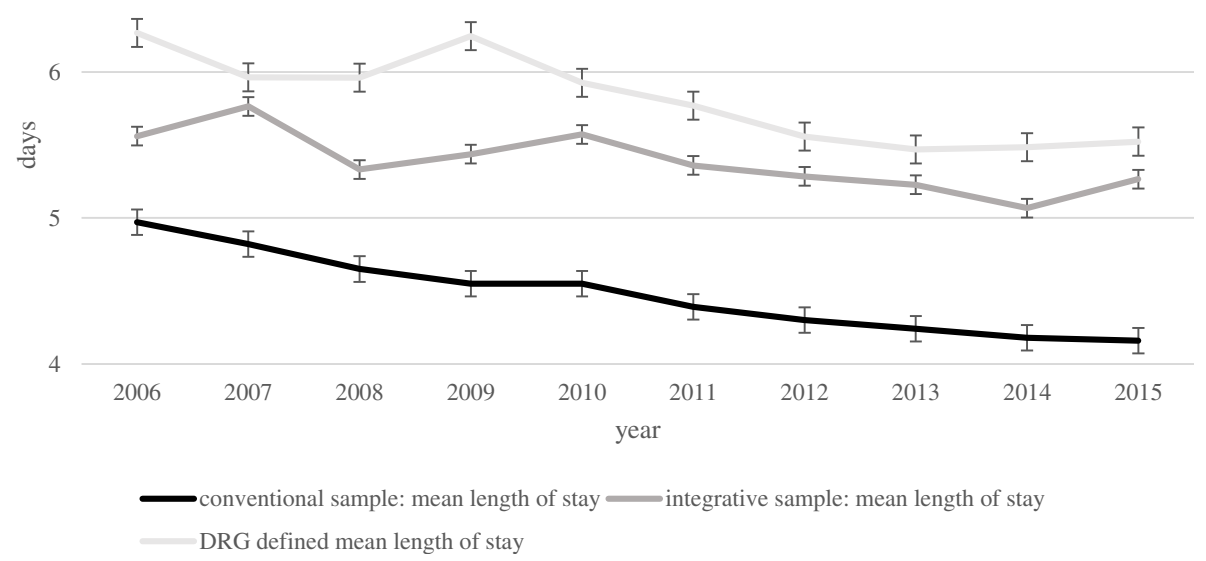

Fig. 2 Mean length of stay in the integrative departments and all German pediatric departments compared to the DRG defined mean length of stay 
17.90\%), Diseases and Disorders of the Respiratory System $(n=4155,13.87 \%)$, Newborn and other Neonates Perinatal Period $(n=4068 ; 13.58 \%)$ and Diseases and Disorders of the Digestive System $(n=4007 ; 13.38 \%)$. In the entirety of all pediatric departments in Germany sample the most frequent MDC were Diseases and Disorders of the Digestive System ( $n=1,502,678 ; 23.50 \%)$; Diseases and Disorders of the Respiratory System $(n=1$, 066,127; 16.67\%); Diseases and Disorders of the Nervous System ( $n=876,894 ; 13.71 \%)$; Diseases and Disorders of the Ear, Nose, Mouth and Throat ( $n=671,922 ; 10.51 \%)$. The percentages of the MDC compared in both samples are presented in Fig. 3.

There were some significant differences in the frequencies of the MDCs between the integrative pediatric departments and all German pediatric departments. Higher frequencies in the integrative sample were observed for the MDC: Newborn and other Neonates Perinatal Period (IPD: $13.88 \%$ vs. $0.87 \%)$; Alcohol, Drug Use, Induced Mental Disorders (IPD: 8.57 vs. 3.32\%); Mental Diseases and Disorders (IPD: $4.27 \%$ vs. 1.16\%); Diseases and Disorders of the Endocrine, Nutritional and Metabolic System (IPD: 7.43 vs 2.74); Diseases and Disorders of the Nervous System (IPD: $17.90 \%$ vs $13.71 \%$ ).

Lower frequencies in the integrative sample were observed for the MDCs:
Pregnancy, Childbirth and Puerperium (IPD: 0.0\% vs 9.6\%); Diseases and Disorders of the Digestive System (IPD: $13.87 \%$ vs 23.05\%); Diseases and Disorders of Ear, Nose, Mouth and Throat (IPD: 4.69\% vs. 10.51\%); Diseases and Disorders of the Respiratory System (IPD: 13.87\% vs. 16.67\%).

\section{Discussion}

In this study, we aimed to investigate resource utilization parameters of integrative anthroposophic pediatric departments and to compare them to corresponding data from all pediatric departments in Germany. In accordance with our initial hypothesis, we found no difference between pediatric integrative anthroposophic departments and the entirety of all pediatric departments concerning effective Case Mix Index. The length of stay in the integrative departments was shorter than the mean DRG-defined mean length of stay and within upper and lower limits, which was in line with our hypothesis.

Furthermore, we hypothesized that these department do not differ from the entirety considering patients' length of stay. Contrary to this hypothesis, we found that the mean length of stay was significantly longer in the integrative anthroposophic departments compared to all German pediatric departments. Another hypothesis was that the departments do not differ considering the frequency distribution of DRG and MDC. Our data did not support this

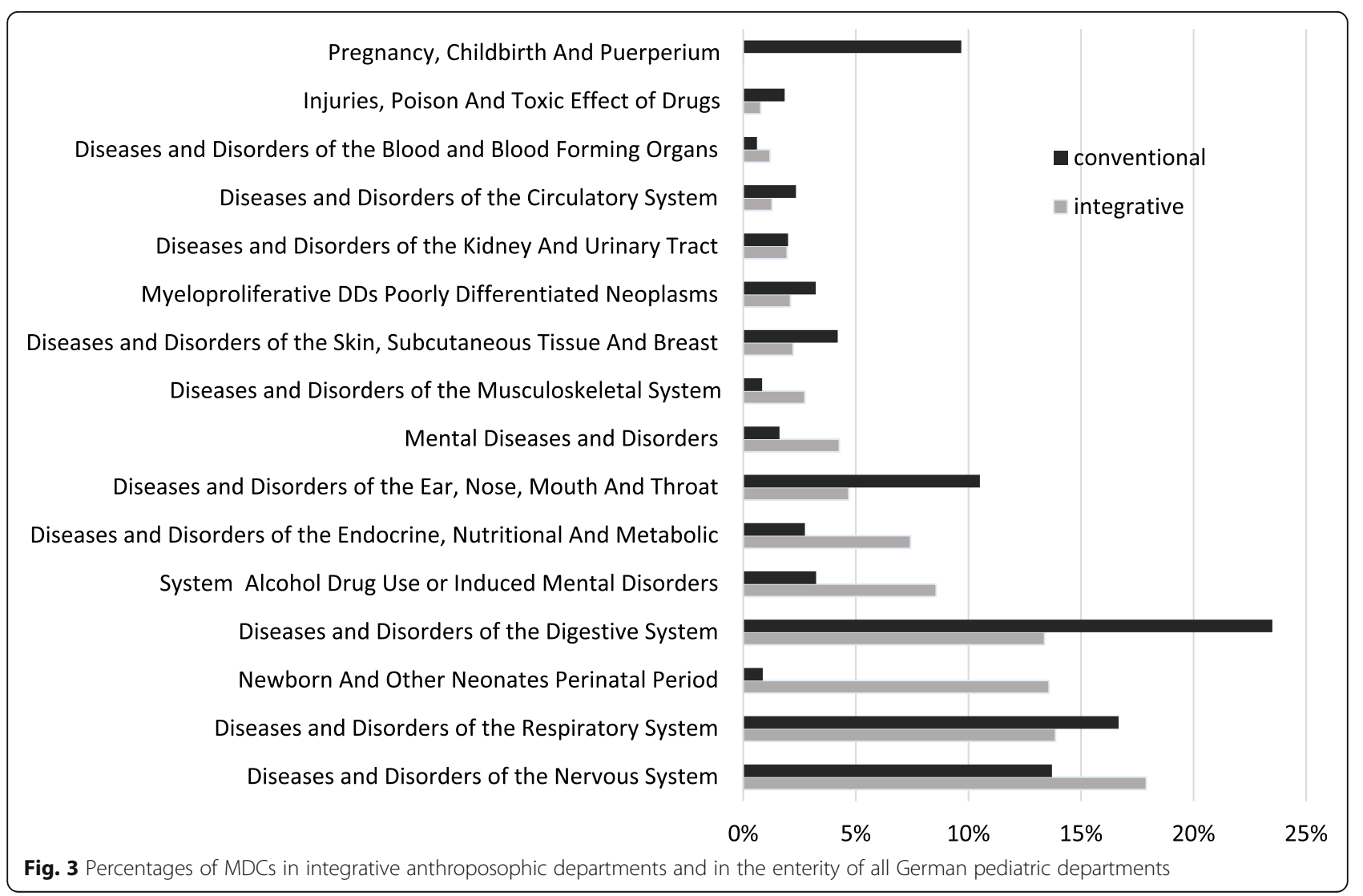


hypothesis, but much more implied some systematic discrepancies between the integrative anthroposophic pediatric departments and all German pediatric departments.

\section{Length of stay}

The average length of stay in the integrative sample was significantly lower than the mean length of stay defined by DRG. It did furthermore, not exceed the upper limit of length of stay defined by DRG or undercut the lower limit of length of stay defined by DRG. This result implies that integrative pediatric departments in Germany can provide care within the terms of the DRG defined conditions concerning length of stay. In contrast to previous studies, we found no indication for less resource utilization in the integrative departments $[65,66]$.

The mean length of stay in the integrative anthroposophic departments was significantly longer compared to the mean stay in all German pediatric departments. This finding is in line with previous research that found longer length of stay in integrative anthroposophic [51] and integrative naturopathic departments [45]. This circumstance may most likely be due to the large number of time-consuming diagnostic and medical procedures that are associated with integrative anthroposophic treatment. Previous studies found an association of increased length of stay in integrative medical department with the utilization of additional anthroposophic [51] or naturopathic [45] reimbursement, which requires a longer stay.

Considering this, the relative difference of 1 day in the length of stay between the departments is comparatively low. While this difference is statistically significant, the effect size is low. However, in this context, it needs to be stated that outliers with extreme lengths of stay (mainly from the diagnosis spectrum of eating disorders) were excluded prior to analysis.

\section{Effective case mix index}

The mean effective CMI were identical in the integrative sample and in all German pediatric departments. This finding indicates that integrative pediatric departments have comparable resource utilization management to general pediatric departments, which is in line with comparable cost analyses [45].

\section{Diagnosis related groups and major diagnosis categories} In both samples, esophagitis, gastroenteritis, gastrointestinal bleeding, ulcer (G67B; G67C) and head injuries (B80Z) belonged to the most frequent DRG's. The percentages varied between the integrative anthroposophic and all pediatric departments. While newborn $>2499 g$, without complex diagnosis was one of the most frequent DRG's in the integrative anthroposophic sample, otitis media or infections of the upper respiratory tract age $<3$ years (D63Z) was more frequent in the entirety of all German pediatric departments.
The frequencies of the MDCs in the integrative anthroposophic sample showed some significant differences in comparison to the entirety of all pediatric departments in Germany. Higher frequencies could be obtained for MDCs of chronic diagnosis spectrum, such as mental, endocrine, and nervous disorders. Lower frequencies were found for acute diseases, such as digestive, respiratory, and ENT- disorders. A similar pattern was obtained in the DRG frequencies.

This result pattern is known from a previous study of our working group on the patient characteristics and clinical characteristics of integrative anthroposophic pediatric departments in Germany [43]. Furthermore, this result is in line with other international studies that conclude that the use of integrative medicine seems to be more frequent in in children with severe and chronic diseases [7, 16, 3036]. The higher frequency of chronic and severe diseases may be another factor influencing the longer length of stay in the integrative pediatric departments.

The large difference considering the MDC newborns, neonates and diseases of the perinatal period, is most likely due to the specification of the GKH with its center for neonatology. The absence of pregnancy, childbirth, and puerperium in the integrative anthroposophic sample may be explained by the circumstance that the treatment in this MDC is merely used by the gynecologic department in the integrative anthroposophic hospitals but not by the pediatric department. The higher percentage of this MDC in all German pediatric departments may be caused by teenage pregnancies or mothers who are treated in the pediatric department because their neonate child is treated in the pediatric department.

\section{Strengths and limitations}

The aim of the present study was to contribute to the better understanding of resource utilization, as measured by length of stay, in pediatric integrative medicine in Germany. A big strength of this study is that it is the first systematic investigation of a large sample of integrative pediatric resource utilization data with comparison to representative data of the entirety of all pediatric inpatient departments in Germany. One major limitation of this study is that it is a secondary data analysis. We were not able to gain raw data from the German Federal Statistical Office for the entirety of pediatric hospitals in Germany. Consequently, it was not possible to exclude any outliers in this sample. Future analyses also need to look at the impact on resource utilization in primary and outpatient care, as well as rehabilitation and social care where appropriate as they may influence the length of stay of in-patients.

We also recognize that this analysis only provides one aspect of information required for future economic evaluation; sequential services and the use of resources for the entire episode of care were not addressed in this 
study. To do so, data on resource use and their costs between integrated pediatric hospitals and other pediatric hospitals will need to be combined with comparative data on outcomes associated with treatment in these settings. This would include analysis for different population sub-groups, for instance by different MDC. Ideally outcomes would be measured in terms of impact on quality of life so that the health economic gold standard of incremental cost per quality adjusted life year (QALY) gained could then be assessed. It would also be important to look at whether there are differences in patterns of rehospitalization as part of any future economic evaluation.

\section{Conclusions}

The comparison of resource utilization in integrative anthroposophic pediatric departments to the entirety of pediatric departments in Germany shows a heterogeneous pattern of similarities and differences. The effective Case Mix Indices were identical, indicating an equal resource utilization in integrative anthroposophic and all pediatric departments. Treatment within integrative anthroposophic pediatric departments fits well in terms of the DRG defined conditions concerning length of stay, even though integrative pediatric patients has an increased length of stay of averagely 1 day, which is most likely associated to time consuming, complex integrative treatment approaches and to a certain extend to higher amount of chronic and severe diseases. Future economic evaluations are needed to assess whether integrative anthroposophic pediatric departments is cost effective.

\section{Supplementary information}

Supplementary information accompanies this paper at https://doi.org/10. 1186/s12913-020-05782-6.

Additional file 1 Supplemental material 1: 50 most frequent DRG in

intergative anthroposophic departments in Germany.

Additional file 2 Supplemental material 2: 50 most frequent DRGs in the entirety of all pediatric departsments in Germany.

\section{Abbreviations \\ IPD: Integrative Pediatric Departments; CMI: Effective Case Mix Index; DRG: Diagnoses Related Groups; GKH: Gemeinschaftskrankenhaus Herdecke; InEK: Institute for the Hospital Remuneration System; M: Mean; Max: Maximum; MDC: Major Diagnostic Category; Min: Minimum; SD: Standard Deviation; SPSS: Statistical Package for the Social Sciences; STROBE: Strengthening the Reporting of Observational Studies in Epidemiology}

\section{Acknowledgements}

We thank the German National Consensus bureau for the support of this project. We thank David McDaid (London School of Economics) for his valuable feedback and helpful advice.

\section{Authors' contributions}

KF substantially contributed to data acquisition, developed the design of the study, performed the data parametrisation and the statistical analyses, interpreted results and wrote the initial manuscript. AL substantially contributed to data acquisition, designing the study, interpreting the data and writing the initial manuscript. MS and TJZ substantially contributed to data acquisition, designing the study, interpreting the data. $\mathrm{CCH}$ substantially contributed to data parametrisation. JV substantially contributed to data acquisition. TO made substantial contributions to data acquisition, the design of the study, data parametrisation, analysing the data and interpreting the final results. All authors were involved in drafting the manuscript and revising it critically for important intellectual content; all authors gave final approval of the final version to be published. Each author is taking public responsibility and accepts accountability for those portions of the content they have been substantially involved in as described above.

\section{Authors' information}

KF is a Psychologist and Medical Researcher. She is a Consultant for Psychometrics, Statistics and Research Methodology. She specializes in Health Research with a focus on Palliative Care, Integrative Medicine, Educational and Clinical Assessment. She is a Research Fellow, Lecturer, and PhD student at the Chair of Research Methodology and Statistics, Department for Psychology and Psychotherapy at Witten/HerdeckeUniversity. AL is a Professor for Integrative Paediatrics at Witten/Herdecke University, Germany and head of the department of Paediatrics at

Gemeinschaftskrankenhaus Herdecke.

MS is a Biologist, PhD and research fellow at Gemeinschaftskrankenhaus Herdecke.

$\mathrm{CCH}$ is a B. Sc. Psychologist, M.Sc. Student and Research Assistant at Gemeinschaftskrankenhaus Herdecke.

JV head of ARCIM Institute for Academic Research in Integrative Medicine and senior physician at the department of Paediatrics at Filderklinik

Filderstadt.

TJZ senior physician at the department of Paediatrics at

Gemeinschaftskrankenhaus Herdecke.

TO is a Professor for Research Methodology and Statistics in Psychology at the Department of Psychology and Psychotherapy at Witten/Herdecke University, Germany.

\section{Funding}

The project was financially supported by the MAHLE Stiftung (grant number: 150096) and the Christophorus Stiftung (grant number: 335), Germany. All authors have no financial relationships relevant to this article to disclose. The funding bodies had no influence on the design of the study, data collection, statistical analyses, interpretation of results, and in writing the manuscript. Open Access funding enabled and organized by Projekt DEAL.

\section{Availability of data and materials}

Raw data are available only for analysis purposes and only to dedicated staff of our research group. As the original data is patient hospital data we have no permission to share it.

\section{Ethics approval and consent to participate}

The present study is a non-invasive, retrospective cohort study, data were collected as part of routine diagnosis, and treatment, which was not set up as a study or research project. There was no necessity to obtain a vote from a research ethics committee $[60,61]$. This procedure is in accordance with section 15 paragraph 1 of the Model Professional Code for Physicians in Germany [62]. The declaration of Helsinki and the rules for data protection and data security and good epidemiological practice were fully applied [61]. We obtained approval for the scientific use of clinical routine data from the commissary for data privacy protection from the Gemeinschaftskrankenhaus Herdecke and the Filderklinik Filderstadt. Data was anonymized at the point of data acquisition for retrospective analysis.

Consent for publication

Not applicable.

Competing interests

The authors declare that they have no competing interests.

\section{Author details}

${ }^{1}$ Department of Psychology, Chair of Research Methodology and Statistics in Psychology, Witten/Herdecke University, Alfred-Herrhausen-Straße 50, 58448 Witten, Germany. ${ }^{2}$ Department of Pediatrics, Gemeinschaftskrankenhaus 
Herdecke, Gerhard-Kienle-Weg 4, 58313 Herdecke, Germany. ${ }^{3}$ Professorship for Integrative Pediatrics, Institute for Integrative Medicine, Witten/Herdecke University, Alfred-Herrhausen-Straße 50, 58448 Witten, Germany. ${ }^{4}$ ARCIM Academic Research in Complementary and Integrative Medicine, Filderstadt, Germany. ${ }^{5}$ Department of Neonatology, University Hospital Tuebingen, Calwerstraße 7, 72076 Tübingen, Germany. ${ }^{6}$ Department of Pediatric Oncology and Hematology, University Hospital Essen, Hufelandstr.55, 45147 Essen, Germany.

Received: 22 April 2020 Accepted: 30 September 2020

\section{Published online: 12 October 2020}

\section{References}

1. What is Integrative Medicine? The Andrew Weil Center for Integrative Medicine. https://integrativemedicine.arizona.edu/about/definition.html. Accessed 12 Aug 2020.

2. Ramesh G, Gerstbacher D, Arruda J, Golianu B, Mark J, Yeh A. Pediatric integrative medicine in academia: Stanford Children's experience. Children. 2018;5:168.

3. Goldstein DS. Sympathetic noradrenergic and Adrenomedullary hormonal Systems in Stress and Distress. In: Squire LR, editor. Encyclopedia of neuroscience. Oxford: Academic Press; 2009. p. 673-8. https://doi.org/10 1016/B978-008045046-9.00098-X.

4. Witt CM, Pérard M, Berman B, Berman S, Birdsall TC, Defren H, et al. Using the framework of corporate culture in "mergers" to support the development of a cultural basis for integrative medicine-guidance for building an integrative medicine department or service. Patient Prefer Adherence. 2015:9:113.

5. Anheyer D, Anheyer M, Finetti C, Dobos G, Cramer H. Implementierung von Phytotherapie in eine Akutklinik für kinder-und Jugendmedizin. Z Für Phytother. 2018;39:251-6

6. Armishaw J, Grant CC. Use of complementary treatment by those hospitalised with acute illness. Arch Dis Child. 1999:81:133-7.

7. Chan E, Rappaport LA, Kemper KJ. Complementary and alternative therapies in childhood attention and hyperactivity problems. J Dev Behav Pediatr. 2003;24:4-8.

8. Eckert M, Amarell C, Anheyer D, Cramer H, Dobos G. Integrative pediatrics: successful implementation of integrative medicine in a German hospital setting—concept and realization. Children. 2018;5:122.

9. Highfield ES, McLellan MC, Kemper KJ, Risko W, Woolf AD. Integration of complementary and alternative medicine in a major pediatric teaching hospital: an initial overview. J Altern Complement Med. 2005;11:373-80.

10. Kemper K, Sarah R, LicAc MPH, Silver-Highfield E, Xiarhos E, Barnes L, et al. On pins and needles? Pediatric pain patients' experience with acupuncture. Pediatrics. 2000;105(Supplement 3):941-7.

11. Kemper KJ, Wornham WL. Consultations for holistic pediatric services for inpatients and outpatient oncology patients at a children's hospital. Arch Pediatr Adolesc Med. 2001:155:449-54.

12. Ottolini MC, Hamburger EK, Loprieato JO, Coleman RH, Sachs HC, Madden $\mathrm{R}$, et al. Complementary and alternative medicine use among children in the Washington, DC area. Ambul Pediatr. 2001;1:122-5.

13. Roth I, Highfield L, Cuccaro P, Wells R, Misra S, Engebretson J. Employing evidence in evaluating complementary therapies: findings from an ethnography of integrative pain Management at a Large Urban Pediatric Hospital. J Altern Complement Med. 2019;25:S95-S105.

14. Sanders H, Davis MF, Duncan B, Meaney FJ, Haynes J, Barton LL. Use of complementary and alternative medical therapies among children with special health care needs in southern Arizona. Pediatrics. 2003;111:584-7.

15. Sawni-Sikand A, Schubiner H, Thomas RL. Use of complementary/ alternative therapies among children in primary care pediatrics. Ambul Pediatr. 2002;2:99-103.

16. Kemper KJ, Gardiner P, Birdee GS. Use of complementary and alternative medical therapies among youth with mental health concerns. Acad Pediatr. 2013;13:540-5

17. Kundu A, Tassone RF, Jimenez N, Seidel K, Valentine JK, Pagel PS. Attitudes, patterns of recommendation, and communication of pediatric providers about complementary and alternative medicine in a large metropolitan children's hospital. Clin Pediatr (Phila). 2011;50:153-8.

18. McClafferty H, Vohra S, Bailey M, Brown M, Esparham A, Gerstbacher D, et al. Pediatric integrative medicine. Pediatrics. 2017;140:e20171961.
19. Stubblefield S. Survey of complementary and alternative medicine in pediatric inpatient settings. Complement Ther Med. 2017;35:20-4.

20. Vohra S, Surette S, Mittra D, Rosen LD, Gardiner P, Kemper KJ. Pediatric integrative medicine: pediatrics' newest subspecialty? BMC Pediatr. 2012;12:123.

21. Bishop FL, Prescott P, Chan YK, Saville J, von Elm E, Lewith GT. Prevalence of complementary medicine use in pediatric cancer: a systematic review. Pediatrics. 2010;125:768-76.

22. Huber BM, Schneider R, Bapst V, Wildhaber J. Integrative Pädiatrie am HFR Freiburg - Kantonsspital. Paediatrica. 2018;29:1.

23. Längler A, Zuzak TJ. Complementary and alternative medicine in paediatrics in daily practice - a European perspective. Complement Ther Med. 2013;21: S26-33.

24. Shapiro S, Rapaport R. The role of complementary and alternative therapies in pediatric diabetes. Endocrinol Metab Clin N Am. 2009;38:791-810.

25. von Schoen-Angerer T, Vagedes J, Schneider R, Vlach L, Pharisa C, Kleeb S, et al. Acceptance, satisfaction and cost of an integrative anthroposophic program for pediatric respiratory diseases in a Swiss teaching hospital: an implementation report. Complement Ther Med. 2017;40:179.

26. Gottschling S, Gronwald B, Schmitt S, Schmitt C, Längler A, Leidig E, et al. Use of complementary and alternative medicine in healthy children and children with chronic medical conditions in Germany. Complement Ther Med. 2013;21:S61-9.

27. Senel HG. Parents' views and experiences about complementary and alternative medicine treatments for their children with autistic spectrum disorder. J Autism Dev Disord. 2010;40:494-503.

28. Vlieger AM, Blink M, Tromp E, Benninga MA. Use of complementary and alternative medicine by pediatric patients with functional and organic gastrointestinal diseases: results from a multicenter survey. Pediatrics. 2008; 122:e446-51.

29. Zuzak TJ, Zuzak-Siegrist I, Simões-Wüst AP, Rist L, Staubli G. Use of complementary and alternative medicine by patients presenting to a paediatric emergency department. Eur J Pediatr. 2009;168:431-7.

30. Barnes PM, Bloom B, Nahin RL, Stussman BJ. Costs of complementary and alternative medicine (CAM) and frequency of visits to CAM practitioners, United States, 2007; 2009.

31. Bethell C, Kemper KJ, Gombojav N, Koch TK. Complementary and conventional medicine use among youth with recurrent headaches. Pediatrics. 2013;132(5):e1173.

32. Birdee GS, Phillips RS, Davis RB, Gardiner P. Factors associated with pediatric use of complementary and alternative medicine. Pediatrics. 2010;125(2):249.

33. Black LI, Clarke TC, Barnes PM, Stussman BJ, Nahin RL. Use of complementary health approaches among children aged 4-17 years in the United States: National Health Interview Survey, 2007-2012. Natl Health Stat Rep. 2015;10:1.

34. Clarke TC, Black LI, Stussman BJ, Barnes PM, Nahin RL. Trends in the use of complementary health approaches among adults: United States, 2002-2012. Natl Health Stat Rep. 2015;79:1.

35. Simkin DR, Popper CW. Overview of integrative medicine in child and adolescent psychiatry. Child Adolesc Psychiatr Clin. 2013;22:375-80.

36. Hagen LE, Schneider R, Stephens D, Modrusan D, Feldman BM. Use of complementary and alternative medicine by pediatric rheumatology patients. Arthritis Care Res Off J Am Coll Rheumatol. 2003;49:3-6.

37. Kienle GS, Albonico H-U, Baars E, Hamre HJ, Zimmermann P, Kiene H. Anthroposophic medicine: an integrative medical system originating in Europe. Glob Adv Health Med. 2013;2:20-31.

38. Ostermann T, Blaser G, Bertram M, Michalsen A, Matthiessen PF, Kraft K. Effects of rhythmic embrocation therapy with solum oil in chronic pain patients: a prospective observational study. Clin J Pain. 2008;24:237-43.

39. Ranger A, Helmert E, Bott TS, Ostermann T, Als H, Bassler D, et al. Physiological and emotional effects of pentatonic live music played for preterm neonates and their mothers in the newborn intensive care unit: a randomized controlled trial. Complement Ther Med. 2018:41:240-6.

40. Schwermer M, Längler A, Fetz K, Ostermann T, Zuzak TJ. Management of Acute Gastroenteritis in children: a systematic review of Anthroposophic therapies. Complement Med Res. 2018;25(5):321.

41. Wopker P, Schwermer M, Sommer S, Längler A, Ostermann T, Fetz K, et al. Complementary and alternative medicine in the treatment of acute bronchitis in children: a systematic review. Complement Ther Med. 2020:49: 102217.

42. Zuzak TJ, Boňková J, Careddu D, Garami M, Hadjipanayis A, Jazbec J, et al. Use of complementary and alternative medicine by children in Europe: 
published data and expert perspectives. Complement Ther Med. 2013;21: S34-47.

43. Fetz K, Ostermann T, Schwermer M, Appelbaum S, Vagedes J, Zuzak TJ, et al. Do patients of integrative anthroposophic pediatric inpatient departments differ? Comparative analysis to all pediatric inpatients in Germany considering demographic and clinical characteristics. BMC Public Health. 2019;19:1623.

44. Herman PM, Poindexter BL, Witt CM, Eisenberg DM. Are complementary therapies and integrative care cost-effective? A systematic review of economic evaluations. BMJ Open. 2012;2:e001046.

45. Ostermann T, Lauche R, Cramer H, Dobos G. Comparative cost analysis of inpatient integrative medicine-results of a pilot study. Complement Ther Med. 2017;32:129-33.

46. White AR, Ernst E. Economic analysis of complementary medicine: a systematic review. Complement Ther Med. 2000;8:111-8.

47. Busse $R$, group E. Do diagnosis-related groups explain variations in hospital costs and length of stay?-analyses from the EuroDRG project for 10 episodes of care across 10 European countries. Health Econ. 2012;21:1-5.

48. Busse R, Street A. Determinants of hospital costs and performance variation methods, models and variables for the EuroDRG project. Berlin: Universitätsverlag der TU; 2010.

49. Reinhold T, Thierfelder K, Müller-Riemenschneider F, Willich SN. Health economic effects after DRG-implementation-a systematic overview. Gesundheitswesen Bundesverb Arzte Offentlichen Gesundheitsdienstes Ger. 2009;71:306-12

50. Street A, Kobel C, Renaud T, Thuilliez J. How well do diagnosis-related groups explain variations in costs or length of stay among patients and across hospitals? Methods for Analysing routine patient data. Health Econ. 2012:21:6-18.

51. Heinz J, Fiori W, Heusser P, Ostermann T. Cost analysis of integrative inpatient treatment based on DRG data: the example of anthroposophic medicine. Evid Based Complement Alternat Med. 2013;2013.

52. Romeyke T, Stummer H. A study of costs and length of stay of inpatient naturopathy-evidence from Germany. Complement Ther Clin Pract. 2011;17:90-5.

53. Association GA of the WM. World medical association declaration of Helsinki: ethical principles for medical research involving human subjects. J Am Coll Dent. 2014;81:14.

54. Von Elm E, Altman DG, Egger M, Pocock SJ, Gøtzsche PC, Vandenbroucke $J \mathrm{P}$, et al. The strengthening the reporting of observational studies in epidemiology (STROBE) statement: guidelines for reporting observational studies. PLoS Med. 2007;4:e296

55. Schwermer M, Längler A, Fetz K, Ostermann T, Zuzak TJ. Anthroposophic medicine in the treatment of pediatric pseudocroup: a systematic review. Complement Ther Med. 2017;40:185.

56. Edelhäuser F, Hak F, Kleinrath U, Lühr B, Matthiessen PF, Weinzirl J, et al. Impact of colored light on cardiorespiratory coordination. Evid Based Complement Alternat Med. 2013;2013.

57. Aggarwal CC. Outlier analysis. In: Aggarwal CC, editor. Data mining: the textbook. Cham: Springer International Publishing; 2015. p. 237-63. https:// doi.org/10.1007/978-3-319-14142-8_8.

58. Geissler A, Scheller-Kreinsen D, Quentin W, Busse R. Germany: understanding g-drgs. Diagn-Relat Groups Eur. 2011;1:243-71.

59. Verweildauer einer DRG - einfach erklärt mit Schaubild! reimbursement. institute. https://reimbursement.institute/glossar/verweildauer/. Accessed 10 Aug 2020.

60. DRG Abschläge - Berechnung der Abschläge und bildliche Darstellung. reimbursement.institute. https://reimbursement.institute/glossar/drgabschlaege/. Accessed 10 Aug 2020

61. DRG Zuschläge - Berechnung der Zuschläge inkl. bildliche Darstellung reimbursement.institute. https://reimbursement.institute/glossar/drgzuschlaege/. Accessed 10 Aug 2020.

62. InEK GmbH. 2017. http://www.g-drg.de/DRG_Archiv/. Accessed 3 Feb 2018.

63. Schreyögg J, Tiemann O, Busse R. Cost accounting to determine prices: how well do prices reflect costs in the German DRG-system? Health Care Manag Sci. 2006;9:269-79.

64. Schreyögg J, Tiemann O, Busse R. HealthBasket Work Package 6 Health Benefits and Service Costs in Europe SP21-CT-2004-501588, Work Package 6: Approaches for Costing and Pricing in Practice Germany.
Department of Health Care Management, Faculty of Economics and Management ...; 2005.

65. Sarnat RL, Winterstein J, Cambron JA. Clinical utilization and cost outcomes from an integrative medicine independent physician association: an additional 3-year update. J Manip Physiol Ther. 2007;30: 263-9.

66. Hamre HJ, Witt CM, Glockmann A, Ziegler R, Willich SN, Kiene H. Health costs in anthroposophic therapy users: a two-year prospective cohort study. BMC Health Serv Res. 2006;6:65.

\section{Publisher's Note}

Springer Nature remains neutral with regard to jurisdictional claims in published maps and institutional affiliations.
Ready to submit your research? Choose BMC and benefit from:

- fast, convenient online submission

- thorough peer review by experienced researchers in your field

- rapid publication on acceptance

- support for research data, including large and complex data types

- gold Open Access which fosters wider collaboration and increased citations

- maximum visibility for your research: over $100 \mathrm{M}$ website views per year

At BMC, research is always in progress.

Learn more biomedcentral.com/submissions 